\title{
Microwave Drying Machine for Sea Bass Leathers
}

\author{
Tantiviwat Sugchai ${ }^{1, *}$, Sudram Arkom ${ }^{1}$, Chanthong Apirun ${ }^{2}$ and Kerdthongmee Priwan ${ }^{3}$ \\ ${ }^{1}$ Faculty of Industrial Education and Technology Rajamangala University of Technology Srivijaya, 1 Ratchadamnoennok Rd, \\ Boryang Sub-district, Muang District, Songkhla 90000, Thailand \\ ${ }^{2}$ College of Industrial Technology and Management Rajamangala University of Technology Srivijaya, 99 Thongnien Sub-district, \\ Khanom district, Nakhon Sri Thammarat, 80210, Thailand \\ ${ }^{3}$ The Center for Scientific and Technology Equipment, Walailak University, 222 Thaiburi Sub-district, Thasala District \\ Nakhonsithammarat 80161, Thailand \\ *Corresponding author
}

\begin{abstract}
Microwave drying is a dehydration process that is often used to preserve a food or material. In this study, sea bass leathers were dried by microwave technique. In order to improve the productivity, the microwave energy was applied to decrease the drying time. The sea bass leathers were dried to the desired final moisture content, whereby $70-80{ }^{\circ} \mathrm{C}$ hot air for baking are generated by the heating process from magnetrons and three levels, power microwave consists of approximately $60 \%, 50 \%, 30 \%$ and drying time are 15-30 minutes based on power ON per unit of total magnetron respectively. The relation between the final applied parameters of microwave power, number of magnetron and the temperature is presented as well. This method can be applied in dehydration with microwave techniques.
\end{abstract}

Keywords-microwave drying; dehydration; rate of drying; sea bass leathers

\section{INTRODUCTION}

Microwaves refer to the electromagnetic waves in the frequency range of $300 \mathrm{MHz}$ up to $300 \mathrm{GHz}$. Since the great experiments were carried out by Dr. Percy Spencer in 1946, microwave heating has been used widely in food industry [1]. Once the microwave energy is absorbed, polar molecules and ions inside the food will rotate or collide, according to the alternating electromagnetic field and heat is subsequently generated from cooking. Nevertheless, and in agreement with the industrial, only $915 \mathrm{MHz}$ and $2.45 \mathrm{GHz}$ are used for food applications, especially the second due to its worldwide availability. The dissimilar process of dehydration has been reported by other authors, indicating some example of this process is solar drying [2], vacuum drying [3], freeze drying [4], microwave drying [5], microwave vacuum drying [6], microwave freeze drying [7], infrared radiation drying [8], etc.

In general, technology of microwave for food in Thailand domestic is widely used only in household cooking. Nowadays, for the use of microwave technology in the industry. There is no widespread usage. Because of the lack of understanding in the application of microwave heating. In addition, entrepreneurs think that microwave on high technology are composite and may cause more harm than the investigations in the baking process, rather than using another method. In Songkhla, Thailand is the source of the most delicious Seabass because the surrounding white Seabass. The Ko Yo Island area contains both salt water and fresh water, brackish water changes according to the each season of the year, it is the source of the famous sea bass. When the frozen industrial came to carve sea bass and fish meat exported to Japan. There is still leather by the remaining fish. The idea of entrepreneurs (T.M.P.) were converted fish leather to food. The importance of the remaining sea bass leather has dried and fried tried a local distributor. As well as the widely popular both at country and abroad. Usually baked seabass skins, it will consist of 2 ways: baking with solar drying and hot air, but the two methods, it will use for a long period of time to bake. By baking with hot air, frying fish leather successfully will take about 40-50 minutes.

Therefore, this research presents ideas to design with baking by using microwave [9-11], which can reduce production time, and consider the value of food, such as the crunchy and still the same softness as well as storage for long periods as with the traditional hot air drying. There is also a concept that combi-nation of heat from microwave and the hot-air for baking are generated by the heating process from magnetrons.

\section{Relation Of Microwave Heating TheORIES}

The basic equation in microwave heating is a model of transverse electromagnetic (TEM) mode. The microwave with $x$ - and $y$-components of the electromagnetic fields and they are assumed to propagate at frequency $915 \mathrm{MHz}$ or $2450 \mathrm{MHz}$ along the $z$ - component direction. Maxwell's equations manage microwave heating, the electromagnetic wave collaboration with materials [12-13] is expressed in four equations:

$$
\left\{\begin{array}{l}
\nabla \times E=-\frac{\partial B}{\partial t}=-j \omega \mu H, \\
\nabla \times H=\sigma E+\frac{\partial D}{\partial t}=(\sigma+j \omega \varepsilon) E, \\
\nabla \square E=0, \nabla \square H=0
\end{array}\right.
$$




$$
\text { or } \quad\left\{\begin{array}{l}
\frac{\partial E_{x}}{\partial z}=\mu_{0} \mu_{r} \frac{\partial H_{y}}{\partial t} \\
\frac{\partial H_{y}}{\partial z}=\varepsilon_{0} \varepsilon_{r} \frac{\partial E_{x}}{\partial t}+\sigma E_{z}
\end{array}\right.
$$

where $E$ is the electric field intensity $(\mathrm{V} / \mathrm{m}), H$ is the magnetic field intensity $(\mathrm{A} / \mathrm{m}), B$ is the magnetic flux density $\left(\mathrm{Wb} / \mathrm{m}^{2}\right)$, $D$ is the electric flux density $\left(\mathrm{C} / \mathrm{m}^{2}\right), t$ is the time, and $D=\varepsilon E$.

Waveguide is a structure that guides waves for electromagnetic waves, it able a signal to propagate with minimal loss of energy by restricting expansion. In microwave oven, the waveguide transfers power from the magnetron, where waves are formed in the baking food. Electromagnetic waveguides are evaluated by explaining Maxwell's equations or their reduced form the electromagnetic wave equation with boundary conditions are determined by the properties of the materials. From Maxwell's equations leading to curl equation is given by

$$
\nabla \times E=-j \omega \mu H, \nabla \times H=j \omega \varepsilon E
$$

The relationship of $E$ and $H$ in the direction of movement in the $z$ - axis, where $E_{i}, H_{i} \propto e^{-\gamma z}(i=x, y, z)$ can be expressed as

$$
\begin{array}{ll}
\frac{\partial E_{z}}{\partial y}+\gamma E_{y}=-j \omega \mu H_{x} & \frac{\partial H_{z}}{\partial y}+\gamma H_{y}=j \omega \varepsilon E_{x} \\
-\gamma E_{x}-\frac{\partial E_{z}}{\partial x}=-j \omega \mu H_{y}, & -\gamma H_{x}-\frac{\partial H_{z}}{\partial x}=j \omega \varepsilon E_{y} \\
\frac{\partial E_{y}}{\partial x}-\frac{\partial E_{x}}{\partial y}=-j \omega \mu H_{z} & \frac{\partial H_{y}}{\partial x}-\frac{\partial H_{x}}{\partial y}=-j \omega \varepsilon E_{z}
\end{array}
$$

where $h^{2}=\gamma^{2}+\omega^{2} \mu \varepsilon$, written in the form of a relationship element in the transverse is as follows:

$$
\begin{aligned}
& E_{x}=-\frac{1}{h^{2}}\left(\gamma \frac{\partial E_{z}}{\partial x}+j \omega \mu \frac{\partial H_{z}}{\partial y}\right), E_{y}=-\frac{1}{h^{2}}\left(\gamma \frac{\partial E_{z}}{\partial y}-j \omega \mu \frac{\partial H_{z}}{\partial x}\right) \\
& H_{x}=-\frac{1}{h^{2}}\left(-j \omega \varepsilon \frac{\partial E_{z}}{\partial y}+\frac{\partial H_{z}}{\partial x}\right), H_{y}=-\frac{1}{h^{2}}\left(j \omega \varepsilon \frac{\partial E_{z}}{\partial x}+\gamma \frac{\partial H_{z}}{\partial y}\right)
\end{aligned}
$$

TEM mode, electromagnetic wave is $E_{z}=H_{z}=0$, TE mode is $E_{z}=0$ and TM mode is $H_{z}=0$ respectively. The Microwave heating is used in the form of the signal transmission cable outlet metal wave that has a rectangular shape with dimensions width by length $b \times a$ is given by

TM mode $E_{z} \neq 0, H_{z}=0$ and $E_{z}=X(x) Y(y) e^{-\gamma z}$

$$
\frac{\partial^{2}}{\partial x^{2}} E_{z}+\frac{\partial^{2}}{\partial y^{2}} E_{z}+h^{2} E_{z}=0
$$

$$
X^{\prime \prime}(x) Y(y) e^{-\gamma z}+X(x) Y^{\prime \prime}(y) e^{-\gamma z}+h^{2} X(x) Y(y) e^{-\gamma z}=0
$$

$$
\frac{d^{2} X}{d x^{2}}+k_{x}^{2} X=0, \frac{d^{2} Y}{d y^{2}}+k_{y}^{2} Y=0
$$

The general equation is in the form of a sine function.

$$
\begin{aligned}
& X(x)=A \cos \left(k_{x} x\right)+B \sin \left(k_{x} x\right) \\
& Y(y)=C \cos \left(k_{y} y\right)+D \sin \left(k_{y} y\right)
\end{aligned}
$$

The electric field at the edge of the waveguide, leading the waves to the position $x=0$ and $y=0$

$$
\begin{aligned}
& E_{z} \mid(x=0)=(A \cos (0)+B \sin (0))\left(C \cos \left(k_{y} y\right)+D \sin \left(k_{y} y\right)\right) e^{-\gamma z}=0 \\
& E_{z} \mid(y=0)=\left(A \cos \left(k_{x} x\right)+B \sin \left(k_{x} x\right)\right)(C \cos (0)+D \sin (0)) e^{-y z}=0
\end{aligned}
$$

For TM mode, consider the relationship of the electric field at the edge of the waveguide, leading the waves to the position $x=a$ and $y=b$

$$
\begin{aligned}
& E_{z} \mid(x=a)=E_{0} \sin \left(k_{x} a\right) \sin \left(k_{y} y\right) e^{-\gamma z} \\
& E_{z} \mid(y=b)=E_{0} \sin \left(k_{x} x\right) \sin \left(k_{y} b\right) e^{-\gamma z}
\end{aligned}
$$

Substituting $k_{x}=\frac{m \pi}{a}, \quad k_{y}=\frac{n \pi}{b}$ where $\mathrm{m}, \mathrm{n}$ are $1,2,3,4 \ldots$, $f_{c(m n)}$ is cut off frequency with $\mathrm{m}, \mathrm{n}$ mode whereby all relations leading to the equation are as follows:

$$
\begin{aligned}
& E_{z}=E_{0} \sin \left(\frac{m \pi x}{a}\right) \sin \left(\frac{n \pi y}{b}\right) e^{-\gamma z} \\
& h^{2}=\left(\frac{m \pi}{a}\right)^{2}+\left(\frac{n \pi}{b}\right)^{2} \\
& \gamma_{m n}=\alpha+j \beta_{m n}=\sqrt{\left(\frac{m \pi}{a}\right)^{2}+\left(\frac{n \pi}{b}\right)^{2}-\omega^{2} \mu \varepsilon} \\
& \gamma_{m n}=j k \sqrt{1-\left(\frac{f_{c(m n)}}{f}\right)^{2}}, f_{c(m n)}=\frac{1}{2 \sqrt{\mu \varepsilon}} \sqrt{\left(\frac{m}{a}\right)^{2}+\left(\frac{n}{b}\right)^{2}}
\end{aligned}
$$

For TE mode, equation is as follows:

$$
H_{z}=H_{0} \cos \left(\frac{m \pi x}{a}\right) \cos \left(\frac{n \pi y}{b}\right) e^{-\gamma z}, f_{c(m n)}=\frac{1}{2 \sqrt{\mu \varepsilon}} \sqrt{\left(\frac{m}{a}\right)^{2}+\left(\frac{n}{b}\right)^{2}}
$$

Sea bass leathers are lossy material, they absorbs microwave power and leads to temperature increase. The temperature variation is governed by heat transfer equation [10], [14] which 
describes the space and time behavior of the temperature field is given by

$$
\left\{\begin{array}{l}
\rho C_{P} \frac{\partial T}{\partial t}-\nabla \cdot\left(k_{t} \nabla T\right)=P, \\
\rho C_{P} \frac{\partial T(z, t)}{\partial t}-k_{t} \frac{\partial^{2} T(z, t)}{\partial z^{2}}=P(z, t), \\
\rho C_{P} \frac{\partial T(z, t)}{\partial t}-k_{t} \frac{\partial^{2} T(z, t)}{\partial z^{2}}=\frac{1}{2} \sigma(z, t)\left|E_{x}(z, t)\right|^{2}, \\
\rho C_{P} \frac{\partial T(z, t)}{\partial t}-k_{t} \frac{\partial^{2} T(z, t)}{\partial z^{2}}=\frac{1}{2} \omega \varepsilon_{0} \varepsilon^{\prime \prime}\left|E_{x}(z, t)\right|^{2}
\end{array}\right.
$$

where $\rho, C_{p}$ and $k_{t}$ are material density, specific heat capacity and thermal conductivity respectively. $T$ is the temperature, $P$ is (EM) microwave power dissipation, and $\omega=2 \pi f$ with $f$ being the applied frequency, $\sigma$ is the effective dielectric conductivity. $\varepsilon_{0}$ is the permittivity of free space and $\varepsilon^{\prime \prime}$ is the imaginary part of the permittivity of the material.

The rehydration capacity [15] is described as water gain as follow:

$$
\text { Weight gain }=\frac{W_{t}-W_{d}}{W_{d}}
$$

where $W_{t}$ is weight after rehydration at time $t$ and $W_{d}$ is weight before rehydration at time t respectively.

The Lewis model has been widely applied to predict the thinlayer drying data of food products exhibiting a decreasing drying rate [16], which only takes into account the surface resistance to moisture transfer. The moisture ratio (MR) was calculated using the following equation:

$$
M R=\frac{M_{t}-M_{e}}{M_{0}-M_{e}}
$$

where $M_{t}$ is the experimental moisture content, $M_{e}$ is the equilibrium moisture content and $M_{0}$ is the initial moisture content respectively.

For constant microwave power, decrease in drying rate was same primarily for all pulse ratios [17]. The PR was calculated using the following equation:

$$
\mathrm{PR}=\frac{t_{\text {on }}+t_{\text {off }}}{t_{\text {on }}}
$$

where $t_{\text {on }}$ is magnetron power ON time and $t_{\text {off }}$ magnetron power OFF time, for the example, when ON time and OFF time $30 \mathrm{~s} / 30 \mathrm{~s}\left(\mathrm{PR}=2.0, t_{\text {on }} / t_{\text {off }}\right), 20 \mathrm{~s} / 40 \mathrm{~s}(\mathrm{PR}=3.0)$, and $10 \mathrm{~s} / 50 \mathrm{~s}(\mathrm{PR}=6.0)$.

\section{Prototype of Microwave Drying Machine}

The dimension of rectangular waveguide is important because waveguides are used to transfer electromagnetic power efficiently, has been applied to the construction of heating. Based of theoretical in topic II consideration of prototype of microwave drying machine, the size of this waveguide (b, a) are 11, $6 \mathrm{~cm}$ respectively. From the simulation with MATLAB to find out the cutoff frequency by considering cases of basic mode $m=1, n=0$. The cutoff frequency is $1.36 \mathrm{GHz}$, for cutoff frequency design must less than fundamental frequency $f_{c}<f_{o}$ where $f_{o}=2.45$ GHz. The machine was presented in fully parameterized model develop for microwave drying. All geometrical is shown in Fig. I. This microwave machine consists of many drying cells (6 cell in cavity), each of them is based on the idea of open resonator, each of cell in cavity has own magnetron located in waveguide owner. In addition, the baking trays are also rotated so that heating it across all sectors. All the element of a machine is as shown geometric shapes machine, 3D schematics in Fig. II.
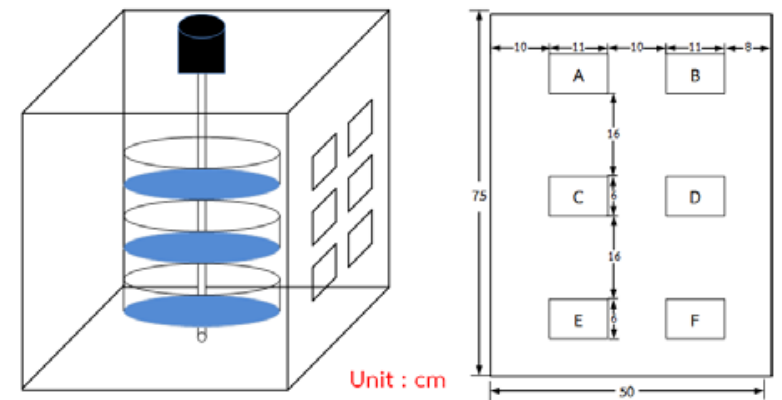

FIGURE I. THE LAYOUT OF WAVEGUIDE IN MACHINE

The microwave drying machine is constructed, as shown in Fig. III., for using the machine can control ON and OFF power of the magnetron, (the power of magnetron has for each size, equal to $1000 \mathrm{~W}$.) with the switch and it can control pulse ratios (PR) for heating sea bass leathers. It can also be control a time for operating of magnetron in microwave cavity by using timer controller. The packaging is composed of a total of eight shelves and can be baked seabass leathers with $2 \mathrm{~kg}$ at a time.

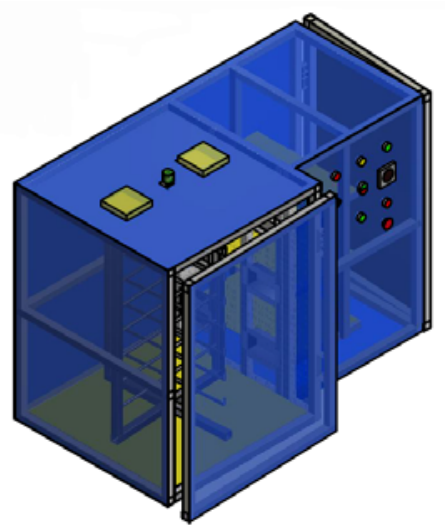

FIGURE II. THE GEOMETRICS SHAPES 3D SCHEMATICS 

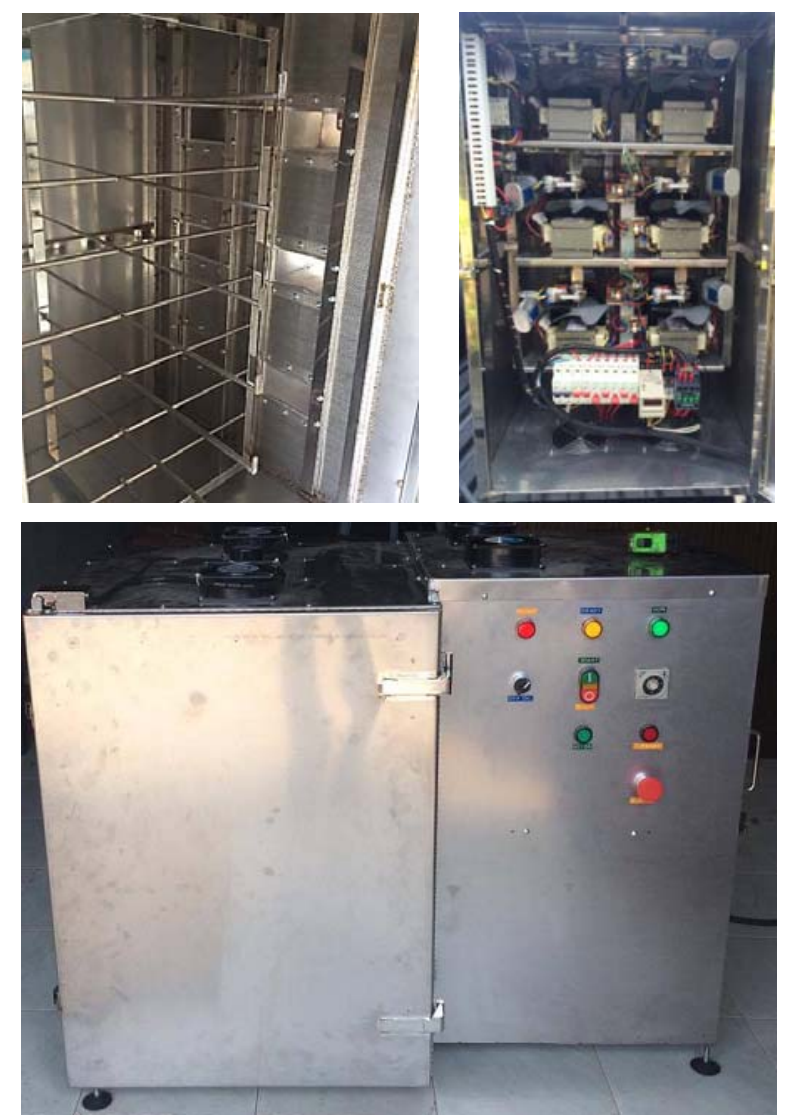

FIGURE III. THE PROTOTYPE OF MICROWAVE DRYING MACHINE

\section{RESULTS AND DisCUSSION}

Preliminary testing machine, the results of moisture in the sea bass leather, found that the moisture content of 20 pieces before baking (measuring 1 piece at a time), there will be moisture equals $3.63-4.75 \%$ moisture after baking and it will have a value of 20 sea bass leather moisture (determination moisture per 1 piece). The moisture equals 2.30 - 3.80\%. From the results it can be seen that the baking of sea bass leather moisture are slightly changed. The results are preliminary information for consideration in baking by microwave drying. However, the problem that is occurring, we can see that the baking material is moist and the process can reduce rate of moisture. This research will have to take into consideration the cost effectiveness, energy consumption and times for baking, as well as the quantity that can be baked in each time. In fact, regardless of the sea bass leathers are not burn or scorch distortion after baking. As well as the taste must remain the same as the original, traditional. From the tested machines can summarize in the Table I. The measured results of microwave drying machine for sea bass leather in Table I. are in good agreement with the measured results of the traditional process but can reduce the time to be a better than in the past of drying.
TABLE I. THE PARAMETER OF MICROWAVE DRYING MACHINE

\begin{tabular}{|c|c|c|c|}
\hline $\begin{array}{c}\text { Power of } \\
\text { magnetron }\end{array}$ & $\begin{array}{c}\text { The number of magnetron } \\
\text { (Position ON) }\end{array}$ & $\begin{array}{c}\text { Range of } \\
\text { Temp. }\left({ }^{\circ} \mathrm{C}\right)\end{array}$ & $\begin{array}{c}\text { Time } \\
\text { (Min.) }\end{array}$ \\
\hline $60 \%$ & 2 (C, D) & $50-70$ & 20 \\
\hline $60 \%$ & 3 (A, D, E), (B, C, F) & $60-80$ & 15 \\
\hline $50 \%$ & 2 (C, D) & $50-70$ & 25 \\
\hline $50 \%$ & $3(\mathrm{~A}, \mathrm{D}, \mathrm{E}),(\mathrm{B}, \mathrm{C}, \mathrm{F})$ & $50-70$ & 20 \\
\hline $30 \%$ & 2 (C, D) & $50-60$ & 30 \\
\hline $30 \%$ & $3(\mathrm{~A}, \mathrm{D}, \mathrm{E}),(\mathrm{B}, \mathrm{C}, \mathrm{F})$ & $50-60$ & 25 \\
\hline $30 \%$ & $4(\mathrm{~A}, \mathrm{C}, \mathrm{D}, \mathrm{F})$ & $50-70$ & 20 \\
\hline
\end{tabular}

\section{CONCLUSIONS}

The results of microwave drying machine for sea bass leathers revealed the following conclusion, increasing drying temperature with microwave power of magnetron can reduce the drying time of sea bass leathers, but sea bass leathers are not burn or scorch distortion after baking. Among the drying parameters are studied, range of temperature are $50-80{ }^{\circ} \mathrm{C}$ and $60 \%, 50 \%$ and $30 \%$ microwave power of magnetron could be mentioned for drying are in good agreement with the measured results of the traditional process but can reduce the time to be a better than in the past methods of drying.

\section{ACKNOWLEDGMENT}

Financial support from government budget of the year 2015, Rajamangala University of Technology Srivijaya is gratefully acknowledged. This work was supported by the Center for Scientific and Technology Equipment, Walailak University.

\section{REFERENCES}

[1] Percy L. Spencer, "Method of treating food stuffs," United state patent office, Application October 8, 1945, Serial No. 620, 919.

[2] B. M. A. Amer, M. A. Hossain and K. Gottschalk, "Design and Performance Evaluation of New Hybrid Solar Dryer for Banana,” Energy Conversion and Management, vol. 51, no. 4, pp. 813-820, April 2010.

[3] F. R. Reis, "Studies on Conventional Vacuum Drying of Foods," Springer Briefs in Applied Sciences and Technology, pp. 7-18, July 2014.

[4] M. Bettge, H. Niculescu and P. J. Gielisse, "Engineered Porous Ceramics Using a Directional Freeze-drying Process,” $28^{\text {th }}$ International Spring Seminar on Electronics Technology: Meeting the Challenges of Electronics Technology Progress, 2005, Wiener Neustadt, 2005, pp. 28-34, 19-20 May 2005.

[5] J. Vrba, M. Stejskal and M. Pourova, "Microwave Drying Machine for Textile Materials,” Microwave Conference, 2009 (EuMC 2009), pp. 1121-1124, 29 September - 1 October 2009.

[6] R. L. Monteiro, B. A. M. Carciofi, A. Marsaioli Jr. and J. B. Laurindo, "How to Make a Microwave Vacuum Dryer with Turntable," Journal of Food Engineering, vol. 166, pp. 276 -284, December 2015.

[7] X. Duan, M. Zhang, A. S. Mujumdar and Shaojin Wang, "Microwave Freeze Drying of Sea Cucumber,” Journal of Food Engineering, vol. 96, no. 4, pp. 491 -497, February 2010.

[8] Z. Pan, C. Shih, T. H. McHugh and E. Hirschberg, "Study of Banana Dehydration Using Sequential Infrared Radiation Heating and Freezedrying," LWT - Food Science and Technology, vol. 41, no. 10, pp. 1944-1951, December 2008.

[9] E. Horuz and M. Maskan, "Hot Air and Microwave Drying of Pomegranate (Punica Granatum L.) Arils,” Journal of Food Science and Technology, vol. 52, no. 1, pp. 285-293, January 2015. 
[10] C. Liu and D. Sheen, "Analysis and Control of the Thermal Runaway of Ceramic Slab Under Microwave Heating," Science in China Series E: Technological Sciences, vol. 51, no. 12, pp. 2233-2241, December 2008.

[11] R. L. Monteiro, B. A.M. Carciofi and J. B. Laurindo, "A Microwave Multi-flash Drying Process for Producing Crispy Bananas,” Journal of Food Engineering, vol. 178(2016), pp. 1-11, June 2016.

[12] D. M. Pozar, “Microwave Engineering,” $2^{\text {nd }}$ ed. New York: Wiley, 1998.

[13] X. Zhao, L. Yan and K. Huang, "Review of Numerical Simulation of Microwave Heating Process,” Advances in Induction and Microwave Heating of Mineral and Organic Materials, Prof. Stanis $\AA$,aw Grundas (Ed.), InTech, pp. 27-48 ch.2, Febuary 2011.

[14] F. Ying, T. Wang, and L. Johan, "Microwave-transmission, Heat and Temperature Properties of Electrically Conductive Adhesive," IEEE Transactions on CPMT, Part A, vol.26, no.1, pp.193-198 March 2003.

[15] S. Tontand and N. Therdthai, "Preliminary Study of Chili Drying Using Microwave Assisted Vacuum Drying Technology," Asian Journal of Food and Agro-Industry, vol. 2, no. 2, pp. 80-86, April 2009.

[16] D. Zhao, K. An, S. Ding, L. Liu, Z. Xu and Z. Wang, “Two-Stage Intermittent Microwave Coupled with Hot-Air Drying of Carrot Slices: Drying Kinetics and Physical Quality,” Food and Bioprocess Technology, vol. 7, no. 8, pp. 2308-2318, August 2014.

[17] S. Gunasekaran, "Pulsed Microwave-vacuum Drying of Food Materials," Drying Technology, vol. 17, no. 3, pp. 395-412, March 1999. 